\title{
Socio-demographic determinants of body mass index among school children in Ebonyi State, Nigeria
}

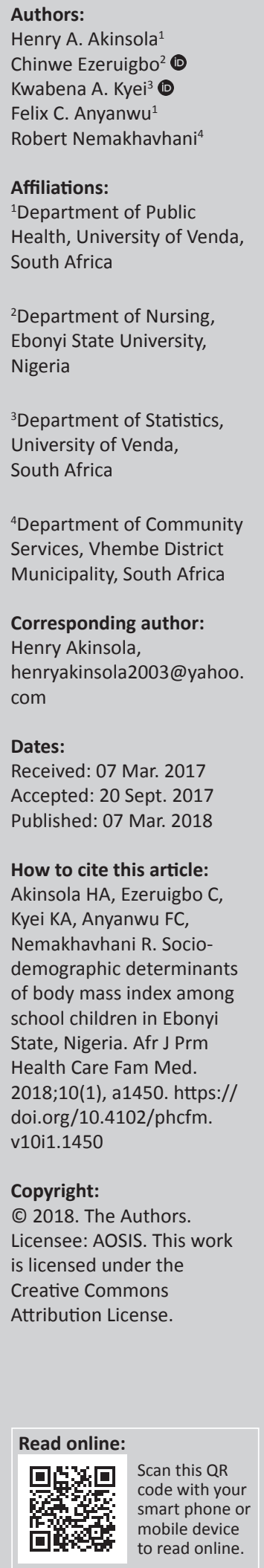

Background: African specific studies on the factors associated with the growth pattern of children are needed to guide evidence and develop effective population-based interventions that can be tailored to the unique African context.

Purpose: The purpose of this study was to determine the socio-economic correlates of body mass index (BMI) of primary and secondary school children in Ebonyi State, which is situated in south-eastern Nigeria.

Methodology: This was a quantitative, cross-sectional study that utilised clustering and stratified sampling techniques to select 1000 learners from primary and secondary schools located in Abakaliki local government area. Apart from a questionnaire, a Mettler weighing scale was also used for data collection. A generalised linear model was used to test the association between the participants' socio-demographic characteristics and their BMI.

Result: BMI was positively related to female gender but negatively related to age and level of education. The mode of cooking, who the participants live with and how they get to school also predicted changes in BMI. Other variables like mother's occupation and family's mode of transport were also associated with BMI changes while father's level of education, mother's level of education, father's occupation and the type of residence did not have any statistical relationship with BMI.

Conclusion: The present study shows that the BMI of school children is influenced by the socio-demographic characteristics surrounding them. Therefore, efforts should be made to improve the socio-economic standing of families in this community.

\section{Introduction}

In different parts of the world, especially in developed countries, studies have shown that both the economic and social context of a child, including a school-age child, are associated with the body mass index (BMI). ${ }^{1,2,3,4,5,6,7,7,9}$ McKay et al. ${ }^{1}$ conducted a survey to examine the influence of economic and social context in relation to abnormal weight and the result showed that both social and economic indicators were predictors of having an above-normal BMI. In a study conducted in the United States, ${ }^{2}$ children from lower-income families had higher prevalence of obesity compared with children from higher-income families. This inverse association was observed among the minority groups in America, such as the Indian, Pacific Island and African children. Grjibovski et al. $^{3}$ found that maternal education and smoking were significant predictors of breastfeeding duration in the 1980s and that the association with measures of adiposity were observed in 15-year-old children and between the children with shortest and longest breastfeeding duration. Musingo and Wang ${ }^{10}$ did a study in which they analysed the eating habits of college students in the United States according to socio-demographic characteristics. The result showed that there were some significant differences in cooking habits, eating fruits and vegetables, residential status of students and socio-demographic characteristics. Furthermore, in terms of drinking habits, analysis by gender indicated that there were significant differences between male and female gender. In another study in the United States, ${ }^{6}$ it was concluded that individual sociodemographic characteristics and school-level socio-demographic composition were associated with obesity among New York City public school children.

According to Oyeyemi et al., ${ }^{11}$ African specific studies on the factors associated with the growth pattern of children are needed to guide evidence and develop effective population-based interventions that can be tailored to the unique African context. Understanding these factors can be critical for establishing a road map to monitor the trend in the growth pattern of school children in African countries, especially in countries like Nigeria where school children are vulnerable to the occurrence of stunted growth or undernutrition because of severe food shortage resulting 
from inflation and currently because of government's inability to pay workers' salary and emoluments. Furthermore, today's children are tomorrow's world leaders and that is why nutritional assessment in the community is important for accurate planning and implementation of intervention programmes to reduce undernutrition-associated morbidity and mortality among children, including school children. ${ }^{12}$

\section{Methodology \\ Design, study population and sampling}

The study was conducted in Abakaliki, the capital of Ebonyi State, which is situated in the south-eastern part of Nigeria. Unemployment is a major problem in the community, especially among the youth. To make ends meet, the majority of the young men use motorcycles (called Okada) to operate public transport business. However, traditionally, the people of Ebonyi State are predominantly farmers while some do fishing as an occupation. The majority of the inhabitants of Abakaliki are characterised by low socio-economic status (SES) and live within low SES areas.

The study included only schools located in Abakaliki local government areas. The design of the study was quantitative, cross-sectional and analytical. After obtaining permission from the Ministry of Education and the principals of the schools involved, using clustering and stratified sampling techniques, one of the researchers and 10 trained research assistants enrolled 1000 learners comprising 500 each from primary and secondary schools situated in Abakaliki. The schools randomly selected through clustering included four private and four public schools. Gender selection was by stratification. After enrolment, participants were briefed about the aim of the study and the process it would involve and informed consent was obtained from their parents or guardian. Height and weight were measured using standardised procedures. For each participant, after taking the measurements, a copy of the questionnaire was completed by a trained research assistant. The questionnaire was based on the study's objectives and validated through literature reconnaissance and several discussions and consultations among the team of researchers. The questionnaire was also pre-tested using 20 learners drawn from the randomly selected schools and amended based on the outcome of the pre-test.

\section{Method of data collection}

Each participant was interviewed individually by 2 members of the research team and 10 trained research assistants. Measurement of weight and height was done by four nurses trained on how to conduct anthropometric measurements on children. Using the Mettler weighing scale (MWS) with a height bar, measurements were taken with the child standing erect and without shoes. Thereafter, the readings were recorded in the space provided at the bottom of the questionnaire. Although the MWS was pre-calibrated, because of the frequent movement of the MWS, it was recalibrated each time it was moved to a different location for data collection. A $10-\mathrm{kg}$ dumbbell was placed on the scale and the reading was taken, the difference observed was used to adjust for the weight of participants.

The BMI for each learner was calculated using the formula $\mathrm{BMI}=$ mass in $\mathrm{kg}$ divided by height in metres (mass $\mathrm{kg}$ / height $\mathrm{m}$ ). The resulting BMI for each participant and their respective ages were then measured against the BMI-for-Age Growth Charts developed by the Centers for Disease Control. ${ }^{13}$ The cut-off is as follows: BMI equal to or greater than the 95th percentile is obesity, BMI less that 95th percentile but greater than 85th percentile is overweight and BMI within the 5 th and the 85 th percentile is normal while BMI below the 5th percentile is underweight.

\section{Method of data analysis}

Considering the nature of the questionnaire which consisted of categorical variables (except the response variable which is derived from two continuous variables [weight and height]), generalised linear model technique was used to test the association between the participants' socio-demographic characteristics and their BMI. Goodness-of-fit test was also used to measure how well the statistical model fits into the set of observations. The measure was done using maximum likelihood estimates which were obtained by finding values that maximised the log-likelihood. The Akaike's Information Criterion (AIC) and deviance statistic were employed as a criterion for judging the quality of the model.

\section{Ethical considerations}

An application for permission to conduct the study was submitted to the Permanent Secretary of the Ministry of Education, Ebonyi State. Upon written approval of the application, approval was obtained from the principal or management of each of the schools involved in the study. With the support of the principals and the school teachers, each child who was recruited to participate in the study was given a consent form for the attention of and action by their parents or guardians. Only those children who returned the signed consent form from their parents or guardians participated in the study.

\section{Results}

A total of 1000 children participated in the study and the majority of them $(82.2 \%)$ were between the age of 10 and 19 years. About 32\% of the children's fathers and 39\% of their mothers were either non-literate or had primary education. Only $25 \%$ and $21.4 \%$ of their fathers and mothers, respectively, were employed either in government or private establishments, while $10 \%$ of their mothers were housewives.

Regarding residence, only about $29 \%$ lived in owned accommodation and $25.8 \%$ in rented single room houses. About $37 \%$ used firewood as the mode of cooking and $43.7 \%$ used kerosene. Fifty-nine percent of the pupils has family own transport, about $76 \%$ went to school on foot and $17.7 \%$ use 
public transport. Over 25\% lived with relatives and over $90 \%$ lived with three or more siblings. About $25.5 \%$ of the children were first born while $17.6 \%$ were last born. The minimum value of BMI was 10.82, the maximum was 31.91 and the mean was 18.43 with a standard deviation of 2.61 .

As shown in Table 1, among children less than 10 years of age, $16(10.7 \%)$ were underweight with a BMI below the 5th percentile, $13(8.7 \%)$ were overweight while $9(6 \%)$ were obese. Among those between 10 and 14 years, $20(4.5 \%)$ were underweight, $24(5.4 \%)$ were overweight while $2(0.5 \%)$ were obese. Furthermore, among those between 15 and 19 years, 46 (12.1\%) were underweight, $7(1.8 \%)$ were overweight and $2(0.5 \%)$ were obese. Considering participants who were older than 20 years, the majority $(67.9 \%)$ had normal BMI while 9 (32.1\%) were underweight.

Table 2 shows that gender, age and participant's level of education are strong predictors of BMI. BMI is positively related to female gender $(p=0.000$; beta $=0.7770)$ but negatively related to age and level of education. This interprets that being of female gender predicts a higher BMI, and the level of BMI increases as age and the level of study decreases.

Table 3 indicates that some of the variables, for instance, the mode of cooking, who the participants live with and how they get to school, have a strong significant change $(p=0.000)$. Although to a lesser extent, some other variables also showed significant change, for instance mother's occupation ( $p=0.047)$ and family's mode of transport $(p=0.021)$, while father's level of education, mother's level of education, father's occupation and the type of residence did not have any

TABLE 1: Body mass index-for-age percentiles.

\begin{tabular}{lccccc}
\hline $\begin{array}{l}\text { Age } \\
\text { (years) }\end{array}$ & \multicolumn{4}{c}{ Percentile (BMI norm) } & Total \\
\cline { 2 - 5 } & $\begin{array}{c}<\text { 5th } \\
\text { (underweight) }\end{array}$ & $\begin{array}{c}\text { 5th to 85th } \\
\text { (normal weight) }\end{array}$ & $\begin{array}{c}>\text { 85th to }<\text { 95th } \\
\text { (overweight) }\end{array}$ & $\begin{array}{c}>\text { 95th } \\
\text { (obese) }\end{array}$ & \\
\hline$<10$ & 16 & 112 & 13 & 9 & 150 \\
$>20$ & 9 & 19 & 0 & 0 & 28 \\
$10-14$ & 20 & 397 & 24 & 2 & 443 \\
$15-19$ & 46 & 324 & 7 & 2 & 379 \\
\hline Total & $\mathbf{9 1}$ & $\mathbf{8 5 2}$ & $\mathbf{4 4}$ & $\mathbf{1 3}$ & $\mathbf{1 0 0 0}$ \\
\hline
\end{tabular}

BMI, body mass index. statistical relationship with BMI. The relationships that are significant are mode of going to school, living with both parents, cooking using firewood $(p=0.000)$, family owning a $\operatorname{car}(p=0.021)$ and mother working as petty trader $(p=0.047)$. The direction of this relationship is however negative for petty trading, both parents living with the child and mode of transport to school, but positively related with cooking with firewood and having a family car. This means that those whose mothers work as petty traders and those who live with both parents are less likely to have high BMI. Those who cook with firewood and those who own a car are more likely to have higher BMI. Table 4 shows that having siblings and the rank of birth have no relationship with BMI changes.

\section{Discussion}

The result shows that a great majority of the children were between the age of 10 and 19 years. This is not surprising considering the fact that in Nigeria, the system of education is referred to as $6,3,3,4$, meaning that a child will spend 6 years for primary education, 3 years for junior secondary, 3 years for senior secondary education and 4 years for the honours university degree programme. And because the minimum age for entry into primary school in Nigeria is 6 years, by the time that the child leaves secondary school, he or she should be about 18 years.

In this study, it was shown that the level of education of the children's fathers and that of the mothers of about one-third was very low and the employment status of many of them was also poor. The other indicators of the children's SES (parents' employment status, residence, mode of cooking, family's mode of transport, mode of transport to school and number of siblings) also showed that many of the study participants came from families with low SES. This might have been responsible for the high prevalence $(14.8 \%)$ of low BMI-for-age seen in this study, which may suggest undernutrition. The results of other studies among school children in Nigeria, agree with this finding, which shows the occurrence of undernutrition in some Nigerian communities. ${ }^{12,14,15,16}$

In 2009, based on the results of their study, Amuta et al. ${ }^{17}$ concluded that the average school child in Markudi, Nigeria,

TABLE 2: The relationship between gender, age, level of education and body mass index.

\begin{tabular}{|c|c|c|c|c|c|}
\hline \multirow{2}{*}{$\begin{array}{l}\text { Parameter } \\
\text { Intercept }\end{array}$} & \multirow{2}{*}{$\begin{array}{c}\text { Coefficient } \\
19.7770\end{array}$} & \multirow{2}{*}{$\begin{array}{c}\text { Significance } \\
0.000\end{array}$} & \multirow{2}{*}{$\begin{array}{c}\text { Wald Chi-square } \\
20194.870\end{array}$} & \multicolumn{2}{|c|}{$95 \%$ confidence interval } \\
\hline & & & & 19.510 & 20.906 \\
\hline \multicolumn{6}{|l|}{ Gender } \\
\hline Female & 0.7770 & 0.000 & 35.583 & 0.522 & 1.033 \\
\hline Male & Reference category & - & - & - & - \\
\hline \multicolumn{6}{|l|}{ Age } \\
\hline$<10$ & -2.8620 & 0.000 & 91.149 & -3.450 & -2.275 \\
\hline$>20$ & -0.8250 & 0.042 & 4.134 & -1.621 & -0.030 \\
\hline $10-14$ & -0.1644 & 0.000 & 44.495 & -2.128 & -1.161 \\
\hline $15-19$ & Reference category & - & - & - & - \\
\hline \multicolumn{6}{|l|}{ Education } \\
\hline Junior secondary & 0.3470 & 0.153 & 2.044 & -0.129 & 0.824 \\
\hline Primary & -1.2280 & 0.000 & 19.315 & -1.776 & -0.680 \\
\hline Senior secondary & Reference category & - & - & - & - \\
\hline
\end{tabular}


TABLE 3: The relationship between family socio-economic profile and body mass index.

\begin{tabular}{|c|c|c|c|c|}
\hline \multirow[t]{2}{*}{ Parameter } & \multirow[t]{2}{*}{ Coefficient } & \multirow[t]{2}{*}{ Significance } & \multicolumn{2}{|c|}{$\begin{array}{c}95 \% \text { Wald confidence } \\
\text { interval }\end{array}$} \\
\hline & & & Lower & Upper \\
\hline Intercept & 19.330 & 0.000 & 18.448 & 20.216 \\
\hline \multicolumn{5}{|l|}{ Father education } \\
\hline Non-literate & 0.646 & 0.095 & -0.113 & 1.404 \\
\hline Primary & 0.281 & 0.316 & -0.268 & 0.830 \\
\hline Secondary & 0.124 & 0.601 & -0.341 & 0.589 \\
\hline Tertiary & Reference category & - & - & - \\
\hline \multicolumn{5}{|l|}{ Mother education } \\
\hline Non-literate & 0.001 & 0.998 & -0.731 & 0.733 \\
\hline Primary & 0.309 & 0.305 & -0.282 & 0.900 \\
\hline Secondary & 0.250 & 0.337 & -0.260 & 0.760 \\
\hline Tertiary & Reference category & - & - & - \\
\hline \multicolumn{5}{|l|}{ Father's occupation } \\
\hline Employed & 0.022 & 0.940 & -0.565 & 0.610 \\
\hline Petty trading & -0.189 & 0.490 & -0.724 & 0.347 \\
\hline Unemployed & 0.153 & 0.674 & -0.560 & 0.866 \\
\hline Well established & Reference category & - & - & - \\
\hline \multicolumn{5}{|l|}{ Mother's occupation } \\
\hline Employed & -0.105 & 0.772 & -0.815 & 0.605 \\
\hline Unemployed & -0.428 & 0.292 & -1.224 & 0.368 \\
\hline Petty trading & -0.640 & 0.047 & -1.271 & -0.008 \\
\hline Well established & Reference category & - & - & - \\
\hline \multicolumn{5}{|l|}{ Residence } \\
\hline Owned bungalow & 0.249 & 0.280 & -0.203 & 0.701 \\
\hline Rented bungalow & 0.026 & 0.940 & -0.650 & 0.702 \\
\hline Rented flat & 0.073 & 0.731 & -0.345 & 0.492 \\
\hline Rented small-room & Reference category & - & - & - \\
\hline \multicolumn{5}{|l|}{ Mode of cooking } \\
\hline Firewood & 1.154 & 0.000 & 0.761 & 1.547 \\
\hline Gas & 0.197 & 0.378 & -0.242 & 0.637 \\
\hline Kerosene & Reference category & - & - & - \\
\hline \multicolumn{5}{|l|}{ Mode of transport } \\
\hline Family car & 0.411 & 0.021 & 0.062 & 0.760 \\
\hline Public transport & Reference category & - & - & - \\
\hline \multicolumn{5}{|l|}{ Living with } \\
\hline Both parents & -0.676 & 0.000 & -1.053 & -0.298 \\
\hline Father & -0.288 & 0.486 & -1.098 & 0.523 \\
\hline Mother & 0.363 & 0.275 & -0.288 & 1.014 \\
\hline Relatives & Reference category & - & - & - \\
\hline \multicolumn{5}{|l|}{ Transport to school } \\
\hline Family car & -1.26 & 0.001 & -1.982 & -0.544 \\
\hline Foot & -1.28 & 0.000 & -1.692 & -0.871 \\
\hline Public transport & Reference category & - & - & - \\
\hline
\end{tabular}

is undernourished. Furthermore, the study by Manyike et al. $^{18}$ on the prevalence of malnutrition among preschool children in Abakaliki, Ebonyi State, showed that the prevalence of global and severe acute malnutrition using $z$-score was $9.7 \%$ and $4.4 \%$, respectfully, while that of stunting was $9.9 \%$ with male preponderance. In another study among school children in Nigeria, ${ }^{14}$ it was clear that an average school child in Ibadan, south-west Nigeria, is undernourished compared to the World Health Organization $(\mathrm{WHO})^{19}$ standard and that of the National Standard for Health Statistics (USA) which is the reference data recommended by the WHO. The importance of food for human development both physically and mentally cannot be overemphasised. ${ }^{14}$ Furthermore, Amuta et al. ${ }^{17}$ thus observed that the need for more calories, protein and micronutrients like iron and
TABLE 4: The relationship between the number of siblings, birth position and body mass index.

\begin{tabular}{lcccc}
\hline Parameter & Coefficient & Significance & \multicolumn{2}{c}{$\begin{array}{c}95 \% \text { Wald confidence } \\
\text { interval }\end{array}$} \\
\cline { 3 - 5 } & & & Lower & Upper \\
\hline Intercept & 17.060 & 0.000 & 15.176 & 18.939 \\
Number of siblings & & & & \\
$\quad 1-2$ & 1.085 & 0.270 & -0.842 & 3.012 \\
3 or more & 1.269 & 0.185 & -0.605 & 3.143 \\
$\quad$ No siblings & Reference category & - & - & - \\
Birth position & & & & \\
First born & 0.283 & 0.162 & -0.114 & 0.680 \\
Last born & 0.339 & 0.135 & -0.106 & 0.783 \\
Only child & 0.212 & 0.804 & -1.459 & 1.883 \\
Other positions & Reference category & - & - & - \\
\hline
\end{tabular}

vitamins for the children, especially those living in the slums cannot be overemphasised. They also emphasised that giving iron tablets or micronutrient fortification is not the answer to the problem of this group of children but what they need is more food which is of good nutritive value. Undernutrition, especially protein energy malnutrition, in young children continues to pose a serious problem in Nigeria, especially among the poorly educated families in low socio-economic brackets that have low purchasing power in the economy. ${ }^{20}$ According to Olanipekun et al., ${ }^{12}$ children from low socioeconomic backgrounds are not likely to have access to nutritious foods. They live in poor houses where unhygienic living standards, unsafe drinking water and unsanitary conditions of the immediate environment prevail. Such environmental factors predispose the children to infections, which adversely affect their growth and nutritional status. ${ }^{20}$

The result of this study shows that gender, age and participant's level of education are strong determinants of BMI among the participants. Specifically, in this study, the female gender had significantly higher BMI scores than those of boys. This finding is consistent with similar studies that reported a higher mean BMI score among the female compared to the male gender. Amuta et al. ${ }^{17}$ attributed this gender differential to the earlier onset of pubertal growth spurt in girls than boys while Olanipekun et al. ${ }^{12}$ attributed it to the fact that girls during this age period are more homely, staying with their mothers in the kitchen and so get some extra portion of food even before the whole family is served. However, it was argued that boys at this age are more active than girls and tend to lose more of their body reserves at active play. ${ }^{12}$ Conversely, in a study in Rwanda, East Africa, generally, a greater proportion of male children were found to have higher BMI scores compared with their female counterparts. $^{21}$

In this study, an inverse relationship was found between BMI level and age as well as the level of study of the participants. In other words, as the age and level of study increased, the BMI level decreased. This might be because of the fact that in developing countries like Nigeria, even in a situation of poverty or lack of food to eat, older children attending secondary schools are more likely to be involved in physical activities, like playing soccer or track events. They are also 
forced by family poverty or harsh socio-economic conditions to engage in child labour early in life, which is energy intensive.

The result of this study shows that children whose mothers work as petty traders and those who live with both parents are less likely to have high BMI. Children whose mothers are petty traders likely belong to families with low socioeconomic backgrounds and hence are most likely not to have enough access to nutritious food, and this might affect their BMI. ${ }^{12}$ It is not surprising that in this study, some children who lived with both parents had lower BMI. More often than not, in Nigeria, most children live with both parents. However, children who live with both parents are more likely to have more siblings and therefore more mouths to feed. According to Owoaje et al., ${ }^{22}$ children from homes with more than four children have a four fold higher risk of developing malnutrition compared to those from homes with four or fewer children. In other words, large family size is a risk factor for undernutrition and thus low BMI. ${ }^{23,24}$

\section{Conclusion}

This study found a high level of low BMI among study participants. Secondly, the study also found that the BMI of school children in the community is influenced by their socio-demographic characteristics. Significantly, 'gender', 'age', 'children's level of study', 'maternal occupation', 'who the children live with', 'mode of cooking' and 'owning a car' were important socio-demographic characteristics associated with abnormal BMI in the community. Based on these conclusions, the paper recommends that in order to develop an effective policy to address the problem of malnutrition among school children in Nigeria, the children's sociodemographic characteristics must be taken into consideration, with particular emphasis on improving the SES of families living in the community.

\section{Acknowledgements}

We thank the Research and Publications Committee (RPC) of the University of Venda for their financial support. We are also thankful to the leadership of the Ebonyi State Ministry of Education for granting us permission to conduct the study and we also appreciate the men and women including school children who participated in this study.

\section{Competing interests}

We declare that the authors have no conflicts of interest in matters relating to this study.

\section{Authors' contributions}

H.A.A. was the lead author. He designed the study and developed the manuscript. C.E. contributed to the study design and supervised data collection. K.A.K. analysed data while F.C.A. and R.N. contributed to data analysis and writing of the manuscript.

\section{References}

1. McKay CM, Bell-Ellison BA, Wallace K, Ferron JM. A multilevel study of the associations between economic and social context, stage of adolescence, and physical activity and body mass index. Pediatrics. 2007;119(1):S84-S91. https:// doi.org/10.1542/peds.2006-2089M

2. Jin Y, Jones-Smith JC. Associations between family income and children's physical fitness and obesity in California. J Prev Chronic Dis. 2012;12:140392. https://doi. org/10.5888/pcd12.140392

3. Grjibovski AJ, Ehrenblad B, Yngve A. Infant feeding in Sweden: Socio-demographic determinants and association with adiposity in childhood and adolescence. Int Breastfeed J. 2008;3:23. https://doi.org/10.1186/1746-4358-3-23

4. Robinson WR, Gordon-Larsen P, Kaufman JS, Suchindran CM, Stevens J. The female-male disparity in obesity prevalence among black Americans young
adults: Contributions of socio-demographic characteristics of the childhood family. Am Soc Nutr. 2009;8:1575-1580. https://doi.org/10.3945/ajcn.2007.25751

5. Greve JM, Gug M, Dulgeroglu D, Brech GC, Castilho A. Relationship between anthropometric factors, gender and balance under unstable conditions in young adults. Biomed Res Int. 2013;2013:850424. https://doi.org/10.1155/2013/850424

6. Rundle A, Richards C, Bader MDM, et al. Individual and school-level sociodemographic predictors of obesity among New York City public school children. Am J Epidemiol. 2012;176(11):986-994. https://doi.org/10.1093/aje/ kws187

7. Leech RM, McNaughton SA, Timperio A. Clustering of children's obesity-related behaviours: Association with demographic indicators. Eur J Clin Nutr. 2013;68(5):623-628. https://doi.org/10.1038/ejcn.2013.295

8. Vezina JW, Der Ananian CA, Greenberg E, Kurka J. Sociodemographic correlates of meeting US Department of Health and Human Services muscle strengthening recommendations in middle-aged and adults. Prev Chronic Dis. 2014;11:140007. https://doi.org/10.5888/pcd11.140007

9. Yen C, Hsiao RC, Ko C, et al. The relationship between body mass index and television viewing, internet use and cellular phone use: The moderating effect of sociodemographic characteristics and exercise. Int J Eat Disord. 2010;43(6):565571. https://doi.org/10.1002/eat.20683

10. Musingo MN, Wang L. Analysis of eating habits according to socio-demographic characteristics of college students. Pak J Nutr. 2009;8:1575-1580. https://doi. org/10.3923/pjn.2009.1575.1580

11. Oyeyemi A, Adegoke BO, Oyeyemi AY, Deforche B, Bourdeaudhuij I, Sallis JF Environmental factors associated with overweight among adults in Nigeria. Int J Behav Act. 2012;9:32. https://doi.org/10.1186/1479-5868-9-32

12. Olanipekun TO, Obatolu VA, Fasoyiro SB, Ogunba BO. Assessment of nutritional status of primary school children in Ibadan, South-West, Nigeria. Nutr Food Sci. 2012;42(6):390-396. https://doi.org/10.1108/00346651211277636

13. Centre for Disease Control. Vital health statistics, Series 11, volume 246 [homepage on the Internet]. 2002 [cited 2016 Mar 12]. Available from: https:// www.cdc.gov/nchs/data/series/sr_11/sr11_246.pdf

14. Samuel OF, Cole AH, Oldewage-Theron WH. Undernutrition and household environmental quality among urban and rural children in Nigeria. Pak J Nutr. 2008;7(1):44-49. https://doi.org/10.3923/pjn.2008.44.49

15. Medhi GK, Barua A, Mahanta J. Growth and nutritional status of school-age children (6-14 years) of tea garden worker of Assam. J Hum Ecol. 2006;19:83-85

16. Goon DT, Toriola AL, Shaw BS, et al. Anthropometric determined nutritional status of urban primary school children in Markudi, Nigeria. BMC Public Health. 2011;11:769-782. https://doi.org/10.1186/1471-2458-11-769

17. Amuta EN, Houmsou U, Soumay R. Assessment of nutritional status of school children in Makurdi, Benue State, Nigeria. Pak J Nutr. 2009;8:691-694. https:// doi.org/10.3923/pjn.2009.691.694

18. Manyike PC, Chinawa JM, Ubesie A, Obu HA, Odetunde OI, Chinawa AT. Prevalence of malnutrition among pre-school children in South-east Nigeria. Ital J Pediatr. 2014;11:40-75. https://doi.org/10.1186/s13052-014-0075-5

19. World Health Organization. Physical status. The use and interpretation of anthropometry [homepage on the Internet]. Volume 854. Technical Report Series. Geneva, 1995 [cited 2017 Aug 02]; 1-452. Available from: https://www.ncbi.nlm. nih.gov/pubmed/8594834

20. ljarotimi OS, Ijaduola KT. Nutritional status and intelligence quotient of primary schoolchildren in Akure community of Ondo state, Nigeria. Tanzan Health Res Bull. 2007;9(2):69-76.

21. Mutandwa E. An examination of socioeconomic determinants of average body mass indices in Rwanda. Open Obes J. 2015;7:1-9. https://doi.org/10.2174/ 1876823701507010001

22. Owoaje E, Onifade O, Desmennu A. Family and socioeconomic risk factors for undernutrition among children aged 6 to 23 months in Ibadan, Nigeria. Pan Afr Med J. 2014;17:161 https://doi.org/10.11604/pamj.2014.17.161.2389

23. Basit A, Nair S, Chakraborthy K, Darshan B, Kamath A. Risk factors for undernutrition among children aged one to five years in Udupitaluk of Karnataka, India: A case control study. Aust Med J. 2012;5(3):163-167. https://doi.org/10.4066/ AMJ.2012.102

24. Lima Mde C, Motta ME, Santos EC, Pontes da Silva GA. Determinants of impaired growth among hospitalized children: A case-control study. Sao Paulo Med J. 2004;122(3):117-123. https://doi.org/10.1590/S1516-31802004000300008 